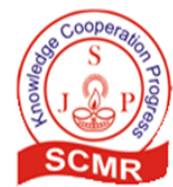

Intemational Joumal of Engineering Sciences 2020 12(4) 146- 151

\title{
Torsion Value Assessment of Human Humerus Bone
}

\author{
Swapnil S. Gaware*, Subim N. Khan ${ }^{\#}$ \\ *PG Student, Mechanical Engineering Department, RSCOE, Pune, India

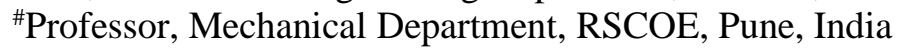

(Received 27 July, 2019: accepted 5 January, 2020)

https://doi.org/10.36224/ijes.120405

\begin{abstract}
Human Bones are very important elements of human body. A bone is a rigid and brittle organ that constitutes part of the vertebral skeleton. The skeletal system is subjected to a complex System of loading exerted by the forces of gravity and the muscles attached to the bones. Such loading modes include tensile, compressive, bending, and torsional forces applied to the bones of the skeletal system. The proposed work is aimed to investigate correlation between HU, STRENGTH \& BMD of humerus bone and evolution of humerus by torsion testing setup. Model of human humerus bone sample obtained from CT- scan in the form of Hounsfield Units (HU) scale and BMD obtained from Dual-Energy X-ray Absorptiometry (DEXA) scan.
\end{abstract}

Keywords: Hounsfield Units, CT-Scan, DEXA

\section{Introduction}

Humerus is a bone in the arm or forelimb that runs from the shoulder to the elbow. It connects the scapula and the two bones of the lower arm, during normal daily activities, the humerus bone is subjected to a complex System of loading exerted by the forces of gravity and the muscles attached to the bone. Such loading modes include tensile, compressive, bending, and torsional forces applied to the bones of the skeletal system, if these forces increased beyond certain limit the chances of bone breaking or cracking are increases this is called fracture, most fracture of humerus are caused by direct blow to the upper arm. This often caused by motor vehicle accident or high impact fall. Less often humerus can fracture because of severe twist of upper arm. Therefore, in evaluating the tolerance limits of bones, it is important to determine the failure behavior of bones under all of these loading Conditions. Now a days in order to study impact properties of bone mechanical setups are available. There are certain cases in which human humerus bone can get fractured due to torsional forces, such as athletic games, wrestling game. In order to study these torsional forces acting on bone, currently no experimental setup is available. So in this project we designed experimental setup for torsion testing.

For the design, analysis and manufacturing of a wide variety of products \& components which are loaded in shear or torsion, the shear stress-strain response of materials pay an important. When the shear force is applied on a specimen, we must know the shear modulus of elasticity and shear yield strength in order to apply the usual closed form equations commonly used in engineering design and analysis. These properties are determined from the shear stressstrain diagram which is most commonly measured according to an ASTM torsion test. In this a material specimen of hollow or solid round cross section is twisted in a machine of torsion 
testing and the angle of twist and applied torque are recorded simultaneously. The torque-twist diagram is constructed from obtained data, and elementary mechanics theory is then used to construct the shear stress-strain diagram. There are number of types of Torsion tests available out of which we will select horizontal chuck holded torsion testing.

\subsection{Horizontal chuck holded torsion}

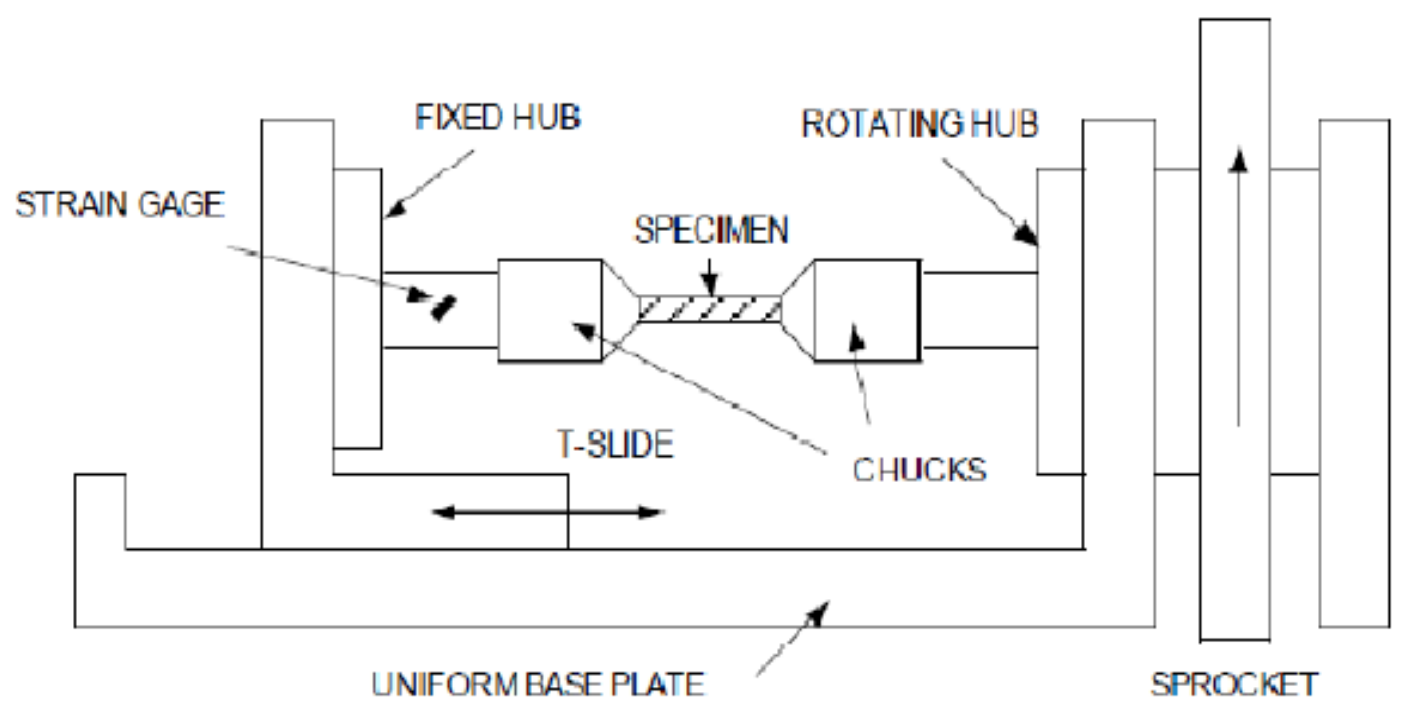

Figure 1: Schematic of the torsion test machine

This is the machine which provides a low cost solution for engineering technology programs that wish to expand their material testing capabilities but however not capable of funding the acquisition of commercially available torsion testing machines.

\section{Literature review}

\subsection{Mechanical properties of Bone by Yuehuei H. An, M. D. Robert, A. Draughn}

The bones are heterogeneous elements because basic components of bones are assembled in different ways, the main factors that affect the bone are loads on bone, type of bone, age of bone and its metabolic activity. There are two types of bones cancellous bone and cortical bone depending on the density of its structure. The bone with very compact state is called as cortical bone and bone with sponge like appearance is called as cancellous bone. Bones are further divided in two types according to their type of fit, the bone with a compact aggregation of collagen fibrils is laminar bone and the bone with loose state is woven bone. As the age of bone increases the woven bone slowly changes and becomes laminar bone. The maintenance and renewal of bone is possible, maintenance of bone is depends on mechanical functions of bone and renewal of bone is on metabolic functions. 
2.2. Relations of mechanical properties to density and CT numbers in human bone J. Y. Rho, M.C. Hobatho and R.B. Ashman

In this study on eight human subjects were made, mechanical properties of cancellous and cortical bones of eight human subjects were calculated by using the ultrasonic transmission technique.

CT scan values of bone are obtained that is raw computerized tomography values are obtained, the scan of bone performed in water and obtained valued are corrected to Hounsfield Units. The comparison of CT numbers obtained and estimated mechanical properties of cortical bone is made and they were found to be low $(\mathrm{r} 2<0 . \mathrm{Z})$, vice versa these relationships for cancellous bone were comparatively high ( $r$ " $>0 . \mathrm{G}\}$.

Obtained results in this study say that c7 values are only useful for predicting the mechanical properties of cancellous bone. If observed deeply at radial and circumferential direction poor correlation zone is found.

\subsection{Biomechanical characteristics of the bone by Antonia Dalla Pria Bank off}

In this section the research in biomechanics of bone is mentioned which contributed to prove the importance of this area of study. This research also brought discussion on the tissue of bones and their biomechanical incorporation in the aspect of human skeleton.

The information present in this was a cited research it placed the bone tissue as a material adaptive levels of loads.

\section{Problem definition}

Humerus bone is subjected to a complex System of loading exerted by the forces of gravity and the muscles attached to the bone. Such loading modes include tensile, compressive, bending, and torsional forces applied to the bones of the skeletal system, if these forces increased beyond certain limit the chances of bone breaking or cracking are increases this is called fracture. So we are going to calculate the stresses induced inside the bone due to torsion phenomenon.

\section{Experimental procedure}

At one end the bone specimen is to be hold firmly and another end is subjected to torque, the breaking angle of the bone and the corresponding values of torque obtained by the experiment can be used for calculating the torsional strength of bone.

\subsection{Working setup}

The specimen of human cortical bone is hold firmly with the help of two clamps. The clamp is to be welded on the movable bracket so that it can slide over the base plate with bracket. As per the specimen length the movable bracket is adjusted and fixed with the help of hexagonal bolts. The rotating clamp rests on the shaft of geared motor with the help of rectangular key. The bone specimen is fixed on the clamp by the bolts with packing material, screwed on the clamp radially. After the proper clamping of bone on two respective clamps, work of hydraulic system begins. To measure the breaking angle the angle Protector is mounted on shaft which rotates along with the same. The moment, at which the bone breaks, the motor is stopped and readings 
are taken. Obtained angle is used in the equations for calculating strength, plotting graphs. The torque was calculated by using the values of pressure obtained using the pressure sensor.

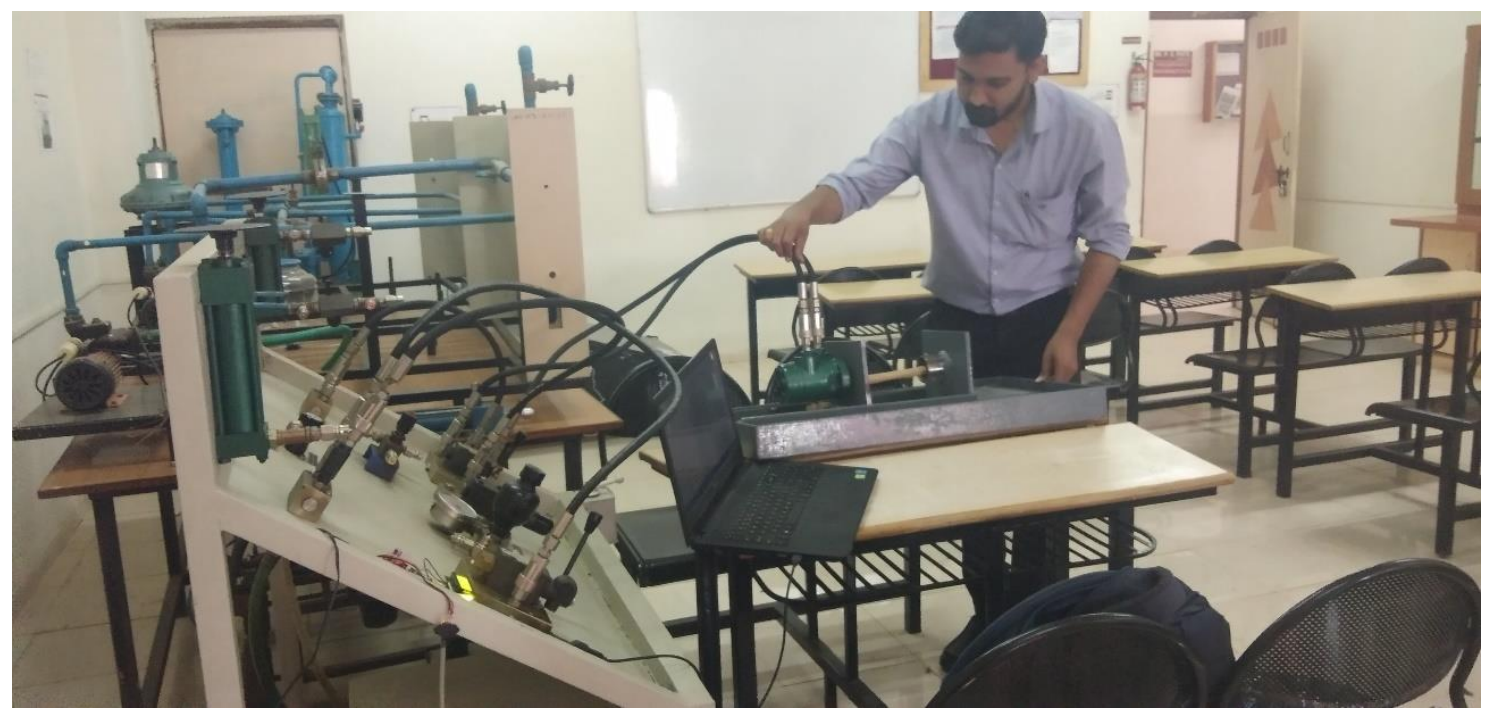

Figure 3: Assembly of all components with motor

\subsection{Experiments}

While performing the experiment, at one end the bone specimen is to be hold firmly and another end is subjected to torque, the breaking angle of the bone and the corresponding values of torque obtained by the experiment can be used for calculating the torsional strength of bone.

In this experimentation the torque is applied using hydraulic geared motor which was fixed to base plate with the help of bolts. The torque can be varied by controlling pressure, similarly the speed can be varied by controlling flow. This experiment is to be performed to record the values for breaking angle and torque.

Table 1: Observation table

\begin{tabular}{|l|l|l|}
\hline Pressure $(\mathrm{Kg} / \mathrm{cm} 2)$ & Torque$(N . m)$. & Angle $\left(\Theta^{\circ}\right)$ \\
\hline 0.435698 & 0.119078 & 2 \\
\hline 1.412356 & 0.370557 & 4 \\
\hline 2.394154 & 0.619137 & 6 \\
\hline 3.360168 & 0.869716 & 8 \\
\hline 4.337095 & 1.122296 & 10 \\
\hline 5.352403 & 1.340713 & 12 \\
\hline 6.3762453 & 1.560131 & 14 \\
\hline 7.3789293 & 1.780548 & 16 \\
\hline 8.4012455 & 1.984965 & 18 \\
\hline 9.4125463 & 2.191533 & 20 \\
\hline 10.4652468 & 2.400101 & 22 \\
\hline 11.5014562 & 2.588668 & 24 \\
\hline 12.5370245 & 2.786236 & 26 \\
\hline 13.5501848 & 2.989836 & 28 \\
\hline 14.563645 & 3.187436 & 30 \\
\hline
\end{tabular}




\subsection{Calculations}

As we know if the cylindrical bar with a length of $\mathrm{L}$, the twisting moment can be related to the shear stress as follows

$$
\frac{\mathrm{MT}}{\mathrm{J}}=\frac{\mathrm{G} \theta}{\mathrm{L}}=\frac{\tau}{\mathrm{r}}
$$

where

$\mathrm{J}$ is the Polar Moment of inertia, in $\mathrm{mm} 2$

$\mathrm{G}$ is the shear modulus, in $\mathrm{N} / \mathrm{mm} 2$

$\Theta^{\circ}$ is the degree of rotation, in radian

$\mathrm{r}$ is the radius of the cylindrical bar, in $\mathrm{mm}$ or in

$\mathrm{L}$ is the length of the cylindrical bar, in $\mathrm{mm}$.

In the elastic region of deformation, the shear stress was calculated according to equation

$$
\tau=\frac{\mathrm{MTr}}{\mathrm{J}}
$$

For a tube specimen, the maximum shear stress at the peripheral of the tube can be calculated from equation,

$$
\tau=\frac{16 \mathrm{M} \mathrm{D} 1}{\pi\left(\mathrm{D} 1^{4}-\mathrm{D} 2^{4}\right)}
$$

where

$\mathrm{D} 1$ is the outer diameter of the tube

D2 is the inner diameter of the tube.

So we can say, if the torque and the degree of rotation are known according to the experimental results, the shear stress and shear strength can be determined from the equation $2 \& 3$.

\section{Results}

Table 2: Result table

\begin{tabular}{|l|l|l|l|}
\hline $\begin{array}{l}\text { Pressure } \\
(\mathrm{Kg} / \mathrm{cm} 2)\end{array}$ & $\begin{array}{l}\text { Torque } \\
(\mathrm{N} . \mathrm{m} .)\end{array}$ & $\begin{array}{l}\text { Strength } \\
(\mathrm{N} / \mathrm{m} 2)\end{array}$ & $\begin{array}{l}\text { Angle } \\
\left(\Theta^{\circ}\right)\end{array}$ \\
\hline 0.426087 & 0.119078 & 16136.05 & 2 \\
\hline 1.402694 & 0.370557 & 50636.02 & 4 \\
\hline 2.379441 & 0.619137 & 85136.11 & 6 \\
\hline 3.360168 & 0.869716 & 119636.01 & 8 \\
\hline 4.337095 & 1.119296 & 154135.7 & 10 \\
\hline 5.34954098 & 1.340713 & 182439.7 & 12 \\
\hline 6.37018695 & 1.560131 & 210745.5 & 14 \\
\hline 7.37983293 & 1.774548 & 239049.4 & 16 \\
\hline 8.3104789 & 1.989965 & 267355.3 & 18 \\
\hline 9.4298403 & 2.202533 & 300755.2 & 20 \\
\hline 10.4702017 & 2.380101 & 334153.3 & 22 \\
\hline 11.4915631 & 2.586668 & 367552.8 & 24 \\
\hline 12.5370245 & 2.785236 & 400951.3 & 26 \\
\hline
\end{tabular}




\begin{tabular}{|l|l|l|l|}
\hline 13.5507848 & 2.991836 & 414336.9 & 28 \\
\hline 14.559645 & 3.190436 & 427719.6 & 30 \\
\hline
\end{tabular}

After performing experiment, the mechanical properties of the bone are correlated as follows:

1. Torque and Theta:

TORQUE $=0.0384203+0.108593 * \Theta^{\circ}-0.0006614 *\left(\Theta^{\circ}-16\right)^{\wedge} 2$

2. HU and APPARENT DENSITY:

$\mathrm{HU}=-687.2363+1.0676009 *$ APPARENT

DENSITY+0.0032374*(APPARENTDENSITY-1155.85)^2

3. Between HU and APPARENT DENSITY:

$\mathrm{Y}=(-1.06 \mathrm{e}-14) \mathrm{X}^{\wedge} 3+(5.557 \mathrm{e}-9) \mathrm{X}^{\wedge} 2-0.00022 \mathrm{X}+374.121 \mathrm{~S}$

\section{Conclusions}

(i) With the help of various methods we can find BMD of bone. E.g. from CT scan data, From DEXA scan.

(ii) The investigation used to get the maximum torque required to break the Humerous Bone during torsion test.

(iii) With the help of this experimental setup we can also find different properties of bone, which are also useful in orthopedic sector for design and manufacturing of implants, research and many other fields.

\section{References}

1. Choi, K. and Goldstein, S.A., A comparison of the fatigue behavior of human trabeculae and cortical bone tissue, Journal Biomechanics, 1992, 25: 1371

2. Egan, J.M., A constitutive model for the mechanical behavior of soft connective tissues, Journal of Biomechanics. 1987, 20: 681-692

3. Fine, K.M., Vegso J.J., Sennett, B., Torg, J.S., Prevention of cervical spine injuries in football. The Physician and Sports Medicine, Vol 19 (10): 54-64

4. Halpbern, B.C., Smith, A. D., Catching the cause of low back pain. The Physician and Sports Medicine, 1991, Vol. 19(6): 71079.

5. Hoffman, A.H., Grigg, P., Measurement of joint capsule tissue loading in the cat knee using calibrated mechano-receptors, Journal of Biomechanics, 22: 787-791

6. Holick, M.F., Perspective on the impact of weightlessness on calcium and bone metabolism,1998, Bone, New York, 1998, v.22, n.5, 105-111

7. Jackson, D.L., Stress fracture of the femur. The Physician and Sports Medicine. 1990, v.9, 39-44

8. Keller, T.S., Spengler, D.M., Regulation of bone stress and strain in the immature andmature rat femur, Journal of Biomechanics. 1989, 22:1115-1127

9. Lakes, R.S.; Nakamura, S.; Behiri, J.C. E.; \& Bonfield, W., Fracture mechanics of bonewith short cracks, Journal of Biomechanics, (1990, 23:967-975

10. McConkey, J.P., Meeuwisse, W., Tibial plateau fractures in alpine skiing. The American Journal of Sports Medicine, 1988, 16: 159-164 